\title{
Pathways in Context
}

\author{
C.J.P. Nolan, A.C.W. Fung and M.A. Brown
}

\section{BACKGROUND}

The contents of this book comprise peer refereed papers selected from the proceedings of the Fourth IFIP (International Federation for Information Processing) Working Conference of Working Group 3.7 on Information Technology and Educational Management (ITEM), held between July 2830, 2000 in Auckland, New Zealand. Preceded by similar conferences in Israel (1994), Hong Kong (1996) and Maine, USA (1998), the 2000 Conference in New Zealand brought together diverse people and presentations that refined and expanded upon the findings of previous conferences. It added to them new findings from ongoing research and it made suggestions regarding possible new directions that computerised information system developments in education might take in the future to support improvement initiatives in schools and other educational institutions.

The focus on improvement emerged almost naturally out of the work of the previous conferences of Working Group 3.7 and, in response to the emerging needs of educational institutions generally, but especially schools. A key need is for computerised information systems that directly support activities and processes central to their operation professionally, technically and in managerial and leadership terms. That is to say, systems are now required that will increasingly permit the broad range of professionals (teachers, department heads, support staff and others) to routinely access and use computerised systems. They need such access and use to support curriculum delivery, the making of strategic decisions about learning and 
teaching, the monitoring and reporting of student progress and the enactment of a wide range of programme review, planning and policy implementation tasks. Fulmer (1995) earlier described both the developments and the needs they would help to meet as constitutive of work in the "technical core" of schools, i.e. curriculum enactment, learning and teaching and evaluation. The work of writers and researchers in IFIP Working Group 3.7 (e.g. Frank and Fulmer, 1998 and Nolan and Lambert, 2001) has since explored this emerging new conception of the use of computerised systems. They locate it in the larger mainstream trend towards the democratisation of school leadership, management and administration. Such a trend reflects, in its turn, the findings of school development and improvement theory and research (Fullan, 1993; Stewart, 2000). The findings identify ways not only that school management and leadership, but also school performance itself can be enhanced through the active engagement of the full range of school personnel in setting policy and in making decisions using computers.

In this respect, the papers selected for this volume constitute a further stage both in the development of computerised information systems for education (and particularly schools) and in our thinking about the possible form and content of such systems in the future. It could be said that system developments and our thinking have progressed through four stages that coincide with each of the ITEM conferences to date.

\section{CONTEXT}

Stage 1 centred around the first (1994) ITEM working Conference in Israel (Barta, et al., 1995) Here, the main emphasis was on frameworks for conceiving, designing and implementing computerised systems. This was at a time when two notions predominated. Firstly, the notion of computer assisted school administration (CASA) placed school administrators and the administrative office of schools at centre stage. Secondly, information technology and educational management was being established as a new field of professional activity, development and research in education (Fulmer et al., 1998). Even at the Israel Conference, though, the concept of computerised school information system (CSIS) was being developed as a broader and more inclusive conception with which to inform development and guide practitioners' understanding of how computer technology might support administrative and management processes in and outside the administrative office.

In 1994, the shift in thinking among developers, researchers and practitioners from exclusive, closed-system designs to inclusive open-system designs had not yet fully occurred. The frameworks presented at that 
conference (e.g. Visscher, 1995) were sufficiently broad in scope and conceptually flexible, however, to accommodate the developments that were to follow and to guide their form and function.

The guiding influence of the frameworks is reflected, for instance, in Fulmer's (1995) theoretical construct of a "good system" which specified key attributes necessary to "collect data, automate processes and informate the work of multiple decision makers from different organisational levels" (Fulmer, op cit. p.7). The attributes are multiple input ports, alternative units of analysis for inquiry, variable types of data, choice of analytic processes and variable access ports for the retrieval of data. Today, most state of the art systems embody these criteria in their designs, range of functionality and operational capabilities. Four such systems were illustrated four years later in the developers workshop for school practitioners at the 1998 ITEM Conference in Maine, with findings reported in the Proceedings (Nolan, et al. 1998). These systems were integrated systems and a wide range of school personnel is increasingly using them routinely for higher order school development activities such as strategic planning, school review and programme design. This does not gainsay the fact that the predominant pattern continues: Computerised information system use remains confined to the administrative office. None the less, a new emerging pattern is also evident. Capable, dedicated and technically proficient practitioners increasingly use computer technology to improve and support learning and teaching, enhance programme design and encourage exemplary professional practice.

Stage 2 centred on the Hong Kong Conference (Fung, et al., 1997) which, by and large, focussed upon the functionality and use of systems and upon conditions that support use. Importantly, however, the Conference in Hong Kong also symbolised the coming of age of Information Technology and Educational Management (ITEM) as a professional entity. It was established as Working Group 3.7 of the International Federation of Information Processing (IFIP) with a mandate to develop a professional and research community, i.e. effectively a community of scholars whose predominant interest is research and development in the emerging new field of ITEM. The members of the community would conduct research, employ the findings of research to inform new developments and produce scholarly outputs for both specialist and general audiences (Nolan and Visscher, 1996). Thus, while the focus of many presentations at Hong Kong was on functionality and use, the broad mandate of the newly formed ITEM Working Group served as a catalyst for development in other directions. This was because the formal mandate of ITEM WG 3.7 was to address not just the development, implementation and use of computerised systems. It was also mandated to address issues and topics related to the context of use, to social and 
normative aspects such as access and equity and to emerging new conceptions of computerised systems.

Such a mandate was timely in 1996 because by then papers presented at the Hong Kong Conference signaled an emerging new trend in thinking about computerised systems. This was towards managing and integrating information with the technology and the new trend identified in 1996 set the scene for the next Conference scheduled for Maine in 1998.

Principally for this reason the Integration of Information for Educational Management became the theme for the 1998 ITEM Working Conference in Maine and this conference accordingly became the hub of Stage 3. It was preceded in the period between conferences by a concerted effort to publish and disseminate to the wider community of educational practitioners and researchers the collective contemporary findings of ongoing research in the field of information technology and educational management. These were contained in a special edition of the International Journal of Educational Research (Visscher 1996) which accurately represented developments in the field, and the predominant focus of computerised system developments around functionality, implementation, use and integration. Visscher (1996) attempted to embody all of this in a single unified and comprehensive School Information System Framework. Vigorous debate ensued, and continues to this day, between Visscher and protagonists (e.g., Fung, 1996; Visscher, Fung and Wild, 1998) and others in WG 3.7 (e.g., Nolan and Ayres 1996, Frank and Fulmer 1998, Nolan and Lambert 2001) about the adequacy of the Framework. In particular, they debated its adequacy to accommodate an emerging new conception of the school as a learning community (Nolan and Lambert, op cit.) as opposed to organisation in the somewhat Weberian sense in which Visscher conceives organisation. The debate indicates the healthy intellectual climate of the Group and it reflects also the commitment of the Group to the norms of collaborative, collegial and reflective practice.

Participants at the 1996 Conference took seriously their wider mandate to address the full spectrum of topics and issues with which practitioners, developers and researchers alike were concerned, or might be concerned in the future. By 1998, a new generation of computerised information systems for schools in particular were available for practitioner use. They were systems with far greater "connectivity" than in the past, in the sense of programes for linking and analysing disparate data and information and for permitting access by mutliple users. That is, they were designed to make practitioner access and use more democratic in the manner previously mentioned (Nolan et al., 1998). The systems could, for instance, generate what Fulmer and Frank (1998) referred to as "teacher valued data" and teachers could access the data and process it in the classroom. In this way, the locus of control over computerised school information system use could 
be decentralised and teachers thereby permitted to generate and analyse data and information useful to them.

Herein lay the germ of an idea for the theme of the ITEM2000 New Zealand Conference: Institutional Improvement through Information Technology in Educational Management. While not expressed using these words in 1998, the tenor and conclusions of many papers (notably, Frank and Fulmer 1998, Nolan et al., 1998 and Tatnall and Tatnall, 1998) indicated a newly emerging concern. This was to address the impact and effects of computerised systems on students and teachers and upon learning and teaching. As one school administrator commented in 1998 during the demonstration of new state of the art systems "the technology being presented to us now, such as Classroom Manager, (an integrated, multifunctional application especially designed for teacher use), is pioneering the way. It could be that we are going to see an absolute explosion in the next ten years in how information can be used in planning, how we spend money, how to arrange classes, and how to plan for the different educational needs of girls and boys" (Maine Elementary Principal, Fulmer, et al., 1998).

Such comment represents a commitment to school improvement as a predominant professional norm of the schools and the teaching profession. More importantly, it represents the mind set of teachers and school administrators that expenditure of scarce school finances on computerised school information systems ultimately is justified in two ways. Firstly, a computerised system can enhance school administration and management at all levels so that overall the school generally operates more smoothly and efficiently with respect to organisational and administrative aspects. Secondly, teacher and administrator use of the system contributes directly to ongoing improvements in learning and teaching, perhaps through improved curriculum planning, better monitoring of student achievement and progress and more effective use of teacher time for teaching and professional development.

At the 2000 Conference, the participants took seriously their responsibility to address the nominated theme of the Conference - the improvement of schools and other educational institutions. And in this way, the focus on improvement symbolised the engagement of WG 3.7 and its dominant concern in Stage 4. Diversity has always been a defining characteristic of WG 3.7, however, and the participants (much smaller in number than at previous conferences, though no less diverse) interpreted the theme in markedly different ways that reflected the diversity of their interests in ITEM and their diverse backgrounds in nine different countries. The countries included Australia, China, England, Japan, New Zealand, The Netherlands, The Philippines, Spain and Slovenia. The professional and 
institutional backgrounds of the participants encompassed school administration, primary and secondary teaching, policy making, research covering systems engineering, business studies, computers in education, software development, and school information system development and design and school advisory roles.

\section{STRUCTURE}

The Chapters in this book, peer refereed internationally by members of the IFIP, W.G. 3.7 programme committee of the Conference, are representative of the distinctive ways that participants addressed the conference theme of school and institutional improvement through the implementation and use of computerised information systems, for education. The contents are in four sections summarised below.

\subsection{Models for supporting and enhancing professional practice}

Contemporary research documents a key role that information technology can, and increasingly does, play in fostering collaborative and productive practice in schools and other educational institutions. Three chapters in Section 1 elaborate on this role for information technology. Two of them (Welsh and Okamoto) describe and examine two models comprising interactive information technology designs for supporting specific aspects of teachers' professional practice. Welsh reports on an IT System for managing the assessment of student learning, developed by teachers in a group of New Zealand secondary schools. Okamoto reports a distance education model within which collaborative communication permits school based curriculum development and teacher training. While the focus of both systems is on support for, and the enhancement of, professional practice, elements within both chapters complement chapters in Section 4 on training and professional development. In a somewhat different vein, the third chapter by Osorio, Zarraga and Rodriguez proposes a collaborative IT framework for educational centres (especially schools and universities) with responsibility for the education of "future knowledge workers". They argue that if educators, and education, are to keep in touch with the social and professional realities for which students are destined, then educational centres must fundamentally changes their missions. In particular, they must change from being providers and disseminators of educational knowledge to being teachers of knowledge management skills that increasingly are commonplace in and valued by, businesses and corporations. To do this, 
educational centres must collaborate and work more in partnership with, rather than isolation from, the business and corporate community.

\subsection{CSIS models and designs}

In the past, computerised information systems commonly were built for the benefit of central educational authorities rather than schools, with the result that many of the systems were inflexible and fail to meet many of the needs of the schools. Such systems tended to address ways of meeting external accountability requirements. They were less than helpful in assisting school managers and administrators to administer their schools internally and to support, in-house, such key school development tasks as curriculum design, the evaluation of programmes and the recording and reporting of student achievement. The chapters in Section 2 identify and examine the characteristics of 'good' computerised school information systems. Additionally, they challenge conventional views about what constitutes a good system. Bajec, Krisper and Rupnik argue that value lies in the application of a Business Rules approach to achieve flexible management and administration system designs, thereby permitting adaptability of use in diverse educational settings. Tatnall and Davies present a case for the development of open systems. This development would be in the direction of system designs that permit users to adapt their systems for specific purposes and integrate new kinds of "third party products" that may either extend the functionality of a given system or change its character. Nolan and Lambert argue that, with schools of the future operating more as learning communities than as organisations, then computerised school information systems designs must increasingly embody design precepts and principles broader than the organisationally orientated spreadsheet designs that currently predominate. Visscher and Bloemen suggest that systems of the future will enable school improvement to the extent that they provide school managers and leaders with tools for autonomous and strategic decision making. The case study they report operationalises a distinction between 'good' and 'bad' practice that managers and administrators employ in supporting staff use of computerised school information systems.

\subsection{Evaluation of system effects}

In the last ten years, a very rapid growth in the number and range of computerised information systems for schools and educational organisations has occurred worldwide. Research is only now being completed which addresses the extent to which computerised systems actually enhance administrative and management practices in education and render them more 
efficient and effective. The chapters in Section 3 report findings from studies of computerised systems that have been widely adopted and used by school systems in two countries, the SIMS (School Information Management System) system in England and SAMS (School Administration and Management System) in Hong Kong, China. While both studies report that the systems contributed to increased administrative efficiency, they also report on limits to effective adoption and use due notably to the relative lack of appropriate and timely professional development and support for users. This factor has been identified elsewhere as vital to successful uptake, adoption andutilisation (Nolan, et al., 2001).

\subsection{Making a Difference through training and professional development}

The research by Nolan, et al. (2001), referred to above, indicates that the timeliness and appropriateness of professional development and training must in the first instance be linked to user concerns and provided in response to them. It must be sensitive to context and be conducted at a pace and in ways that develop confidence and competency progressively. The position taken by Visscher and Branderhorst is that few professional development and training systems exist or are in use that satisfies all of these criteria. They identify and examine the characteristics of effective training systems for school managers. In contrast, Selwood, Smith and Wisehart examine the effectiveness of the National Grid for Learning, which is a British developed Internet-based system for the training and support of school staff in the use of a wide range of IT tools from classroom teaching and learning to school office. The system comprises a "mosaic of interconnecting networks and education services... which supports teaching, learning, training and administration in schools, colleges, universities, libraries, the work place and homes". The system is, in effect, a comprehensive and potentially far reaching, on-line communications network. The effectiveness of its use depends, however, on user access to timely, appropriate and ongoing professional development and training.

In all sections, the chapters address in varying ways the general theme of institutional improvement through and with information technology in educational management - ITEM. The theme reflects, in its turn, the general focus and direction of contemporary mainstream educational and school development research. There, practitioners and researchers alike now acknowledge that, in order to be useful, research and development must be capable of yielding outcomes (insights, understandings and operational principles) that can inform, perhaps change, the thinking and professional judgment of educational practitioners. In this way research and development 
such as that reported in this book might enhance conditions for effective learning and teaching in schools and in the wider education community encompassing agencies and organisations as diverse as early childhood education centres to universities.

The 1998 Conference in Maine, USA included a developer's workshop. Its purpose was to develop the nexus between practitioners (i.e. the users of systems and consumers of research), system developers and designers and researchers. In many respects, the workshop was a highlight of the Conference. This is reflected in the sense of excitement and wonderment reported in the Preface to the Proceedings at what had already been accomplished with information technology, and at what might be accomplished in the near future. In the concluding chapter, Nolan et al. (1998) commented that uptake and use of computerised systems could founder if two conditions are not present. The first is practitioners seeing value in the systems as a means to support and enhance teaching and the learning of children and students. The second is the presence and the development of school and institutional cultures that support innovations such as computerised information systems.

These observations are worth reiterating here in light of a bold new initiative in the Philippines called TAO CARES (Computer Assisted Reforms for Schools) project, outlined in a Conference 2000 presentation by Senator Teresa Aquino-Oreta (Chairperson, Senate Committee on Education, Arts and Culture), though not formally reported here. TAO CARES is a centrally funded Government project which, on the face of it, combines features of both top-down, mandated system developments (Fung, et al., 2001) with bottom-up developments whose mandate is practitioner and school needs and priorities. In the case of the Philippines, it is possible that its two-pronged strategy may result in avoidance of the many pitfalls commonly associated with top-down mandated developments (e.g., user avoidance or rejection). At the same time, it may secure user commitment through engagement of users, and prospective users, in the development, design and piloting process (Nolan, Brown and Graves, 2001).

In a sense, the report on TAO CARES by Aquino-Oreta corresponded with the developers workshop in Maine, 1998. It did so in the sense that the Philippines initiative has the potential to bring together developers, educational practitioners and researchers to form a nexus in the Philippines and with significant others from elsewhere. This could generate design and development, adoption, implementation and utilisation strategies and solutions in a way that has hitherto not happened in other countries. The Philippines' initiative reflects an attitude of optimism and hope for the future, tempered by realism. It is laudable given the contemporary political upheaval of the Philippines and the conditions of impoverishment and 
system-wide lacks of resources endemic in Philippines society generally and in its school and education system, in particular. Nonetheless, the initiators of the TAO CARES project are determined and they understand more than their predecessors in other countries about what must, and can be done to bring about change. Perhaps the presentation on TAO CARES foreshadows the next stage of development for ITEM and its Working Group 3.7 in the International Federation for Information Processing (IFIP). This might be called the Stage 5 - Empowerment: Educational practitioners controlling and using modern computer technology both to lead and manage education and to develop schools as "public good" institutions supporting equity in education and providing educational opportunity for all.

\section{Editors}

Pat Nolan

Alex Fung

Margaret Brown

\section{ACKNOWLEDGEMENTS}

The editors would especially like to thank Philippa Butler for her work as proofreader and Anneke Visser for her typesetting work.

\section{REFERENCES}

Barta, B., Telem, M.\& Gev, Y. (Eds.) (1995) Information technology in educational management. London: Chapman \& Hall.

Fullan, M.G. (1 992). Successful school improvement: The implementation perspective and beyond. Buckingham: Open University Press.

Fulmer, C.L. (1995) Maximising the potential ofinformation technology for management strategies for interfacing the technical core of education. In B.Z. Barta, M. Telem, \& Y. Gev (Eds.), Information technology in educational management. London: Chapman Hall.

Frank, E.P., \& Fulmer, C.L. (1998). The dysfunctional side of educational organizations: Themes from clinical information system development. In C.Fulmer, B.Barta,\& P.Nolan (Eds.), The integration of information for educational management. Whitefield, ME: Felicity Press.

Fung, A.C.W. \& Ledesma,J. (2001). SAMS in Hong Kong schools: A user acceptance audit. In C.J.P. Nolan, A.C.W. Fung, \& M.A. Brown (Eds.), Pathways to institutional improvement with information technology in educational management. London: Kluwer.

Fung, A.C.W., Visscher, A.J., Barta, B., \& Teather, D.C.B. (1997). Information technology in educational management for the schools of the future. London: Chapman and Hall.

Fung, A.C.W. (1996). An evaluation of the Hong Kong design and development strategy. International Journal of Educational Research, 25 (40), 297-305. 
Nolan, C.J.P., \& Ayres, D.A. (1996). Developing a "good" information for schools: The New Zealand experience. International Journal of Educational Research, 25 (5), 307-319.

Nolan, C.J.P. and Visscher, A.J. (1996). Research on information technology in educational management. In J.D. Tinsley and T.J. van Weert (Eds.), Post-conference report on the Sixth IFIP World Conference on Computers in Education. Birmingham: IFIP Technical Committee 3.

Nolan, C.J.P., Fulmer, C.L., \& Taylor, R. (1998).Four computerized school information systems: Summary discussion. In C. Fulmer, B. Barta, \& P. Nolan (Eds.), The integration of information for educational management. London: Kluwer.

Nolan, C.J.P., Brown, M.A., \& Graves, B. (2001). MUSAC in New Zealand: From grass roots to system-wide in a decade. In A.J. Visscher, P. Wild, and A.C.W. Fung (Eds.), Information technology in educational management: School information systems in the 2lst century. The Netherlands: Kluwer.

Nolan, C.J.P., \& Lambert, M. (2001). Information systems for leading and managing schools: Changing the paradigm. In C.J.P. Nolan, A.C.W. Fung, \& M.A. Brown (Eds.), Pathways to institutional improvement with information technology in educational management. London: Kluwer.

Stewart, D. (2000). Tomorrow 's principals today. Palmerston North: Dunmore Print.

Tatnall, A \& Tatnall, B. (1998). Data integration in a training institute: Modelling a clientserver solution. In C.L. Fulmer, B.Z. Barta, \& P. Nolan (Eds.), The integration of information for educational management. Whitefield, Maine: Felicity Press.

Visscher, A. J. (1995). Computer assisted school administration and management: Where we are and where should we go? In B. Barta, M. Telem \& Y. Gev (Eds.), Information technology in educational management. London: Chapman \& Hall.

Visscher, A.J. (1996). The implications of how staff handle information for the usage of school information systems. International Journal of Educational Research, 25 (4), 323334.

Visscher, A.J., Fung, A.C.W., \& Wild, P. (1999). The evaluation of the large scale implementation of a computer-assisted management information system in Hong Kong schools. Studies in Educational Evaluation, 25, 11-31. 